\title{
EXPERIMENTAL PROCEDURE USED TO DETERMINE THE FLEXURAL RIGIDITY FOR COMPOSITE SANDWICH BARS WITH VARIOUS THICKNESS VALUES
}

\author{
MIRITOIU Cosmin Mihai \\ Faculty of Mechanics./Department of Vehicles, Transports and Industrial Engineering, University of Craiova, \\ Craiova, Romania, miritoiucosmin@yahoo.com
}

\begin{abstract}
In this paper there is presented an experimental procedure used to determine the flexural rigidity for composite sandwich bars with polypropylene honeycomb core with various thickness values: 1, 1,5 and $2 \mathrm{~cm}$. The composite bars will be reinforced with one layer of carbon fiber. The width value of the composite bars will be of $6 \mathrm{~cm}$. In order to obtain the flexural rigidity the composite bars will be clamped at one end and left free at the other. An accelerometer will be placed at the free end used to record the free vibrations of these bars. The simplifying assumption of "bar" will be used in this research, so I have chosen several free lengths for the bars: 29, 32 and $35 \mathrm{~cm}$. The eigenfrequency of the first eigenmode will be used to determine the flexural rigidity of the bars.
\end{abstract}

Key words: composite bars, polypropylene honeycomb core, carbon fiber, eigenfrequency

\section{Introduction}

Most of the composite materials used for high strength structures include as reinforcement the carbon fiber. For example, in [1] there are presented some SEM photographs for the structure of porous carbon fiber (abbreviated as PF in the paper) derived from phenolic polymer containing polystyrene micro beads, in this way: photographs of the side surface and the cross-section of the stabilized PF fiber, side surface of the PF fiber after carbonization at $1000^{\circ} \mathrm{C}$ and the cross section of the PF fiber after carbonization at $1000^{\circ} \mathrm{C}$. In [2] there is investigated the effect of fiber orientation on the structure of shock waves in carbon-fiber epoxy composites of various symmetry. In [3] there is used a mechanical model with one degree of freedom to study the vibrations of epoxy- Kevlar-carbon and epoxy- carbon bars. There were obtained calculus formulas for the eigenfrequency and damping factor as a function of the bars free length. There were considered four variants of free length. In [4] there are studied several composite sandwich bars with different core (polystyrene or polypropylene honeycomb) and reinforcement (steel wire mesh, carbon fiber or glass fiber). The main conclusion was that, no matter what type of core was used, the composite bars reinforced with carbon fiber have the highest stiffness and damping factor.

In [5] there was investigated the EP142-C510-50 woven carbon fiber composite was investigated from mechanical and structural point of view for usage in the aeronautical industry. At $160^{\circ} \mathrm{C}$, the carbon fiber was combined with epoxy resin. There were applied the next loading tests: 3 points bending, tenstile and fatigue tests. SEM images were also presented with the broken samples sections. Other tests, for construction materials including the composite ones, are also presented in [6] and [7]. Other carbon fiber researches are also made in [8], [9] and [10].

\section{Experimental procedure for flexural rigidity determination}

I have made some composite bars with polypropylene honeycomb core (with 1, 1,5 and $2 \mathrm{~cm}$ thickness) reinforced with one layer of carbon fiber (on the upper and lower sides of the bars). The width of the bars is $6 \mathrm{~cm}$. The used samples are presented in fig. 1 and marked in this way: sample 1 (thickness $1 \mathrm{~cm}$ ), sample 2 (thickness $1,5 \mathrm{~cm}$ ) and sample 3 (thickness $2 \mathrm{~cm}$ ). To obtain the flexural rigidity I have considered the next experimental montage: I have clamped the bars at one end and left them free at the other one. At the free end I have placed an accelerometer and I have recorded the free vibrations of the bars (the vibrations were obtained after applying an initial force). I have used the SPIDER 8 data acquisition system, the NEXUS signal amplifier. All the experimental data were stored on a notebook connected through port USB to SPIDER 8. 
In order to apply the bar simplifying assumption for the studied samples I have used several values for the samples free lengths: 29,32 and $35 \mathrm{~cm}$. The connection between the core and the reinforcement was done by using epoxy resin with its hardener. The moulding procedure was made at room temperature. According to [4], the free vibrations experimental recordings can be used to determine the eigenfrequency of the first eigenmode with formula (1).

$$
v=T^{-1}
$$

In (1) I have marked with $T$ the double time gap between two consecutive cancellations. Also, (2) can be used for the damping factor calculus.

The experimental recordings and the eigenfrequency calculus for the sample 1 are presented in fig. 2, 3, 4, 5, 6 and 7.

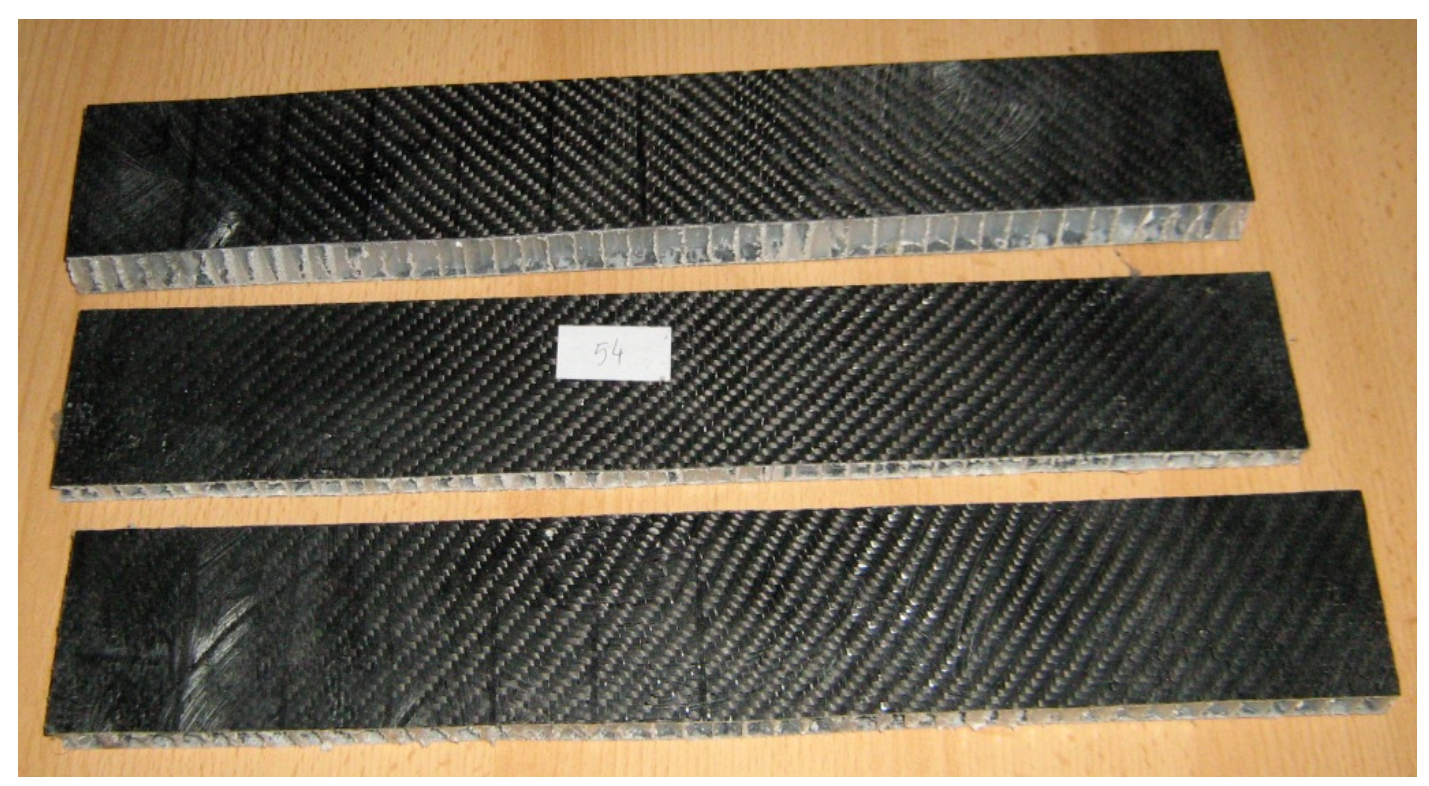

Figure 1: A general presentation of the used samples

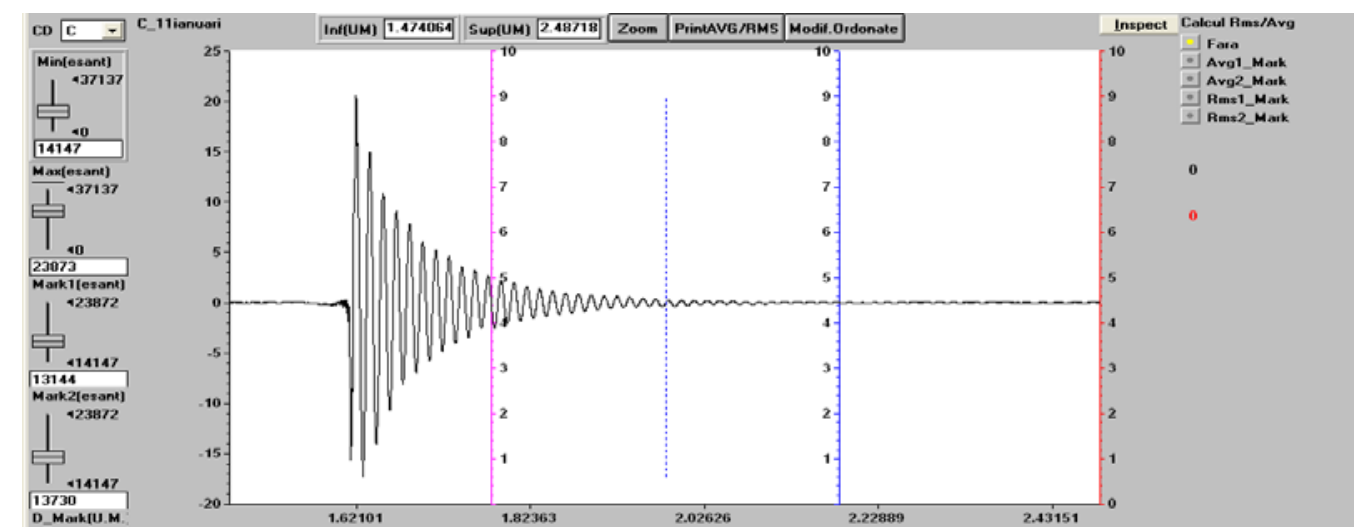

Figure 2: Experimental recordings (sample 1, free length $29 \mathrm{~cm}$ )

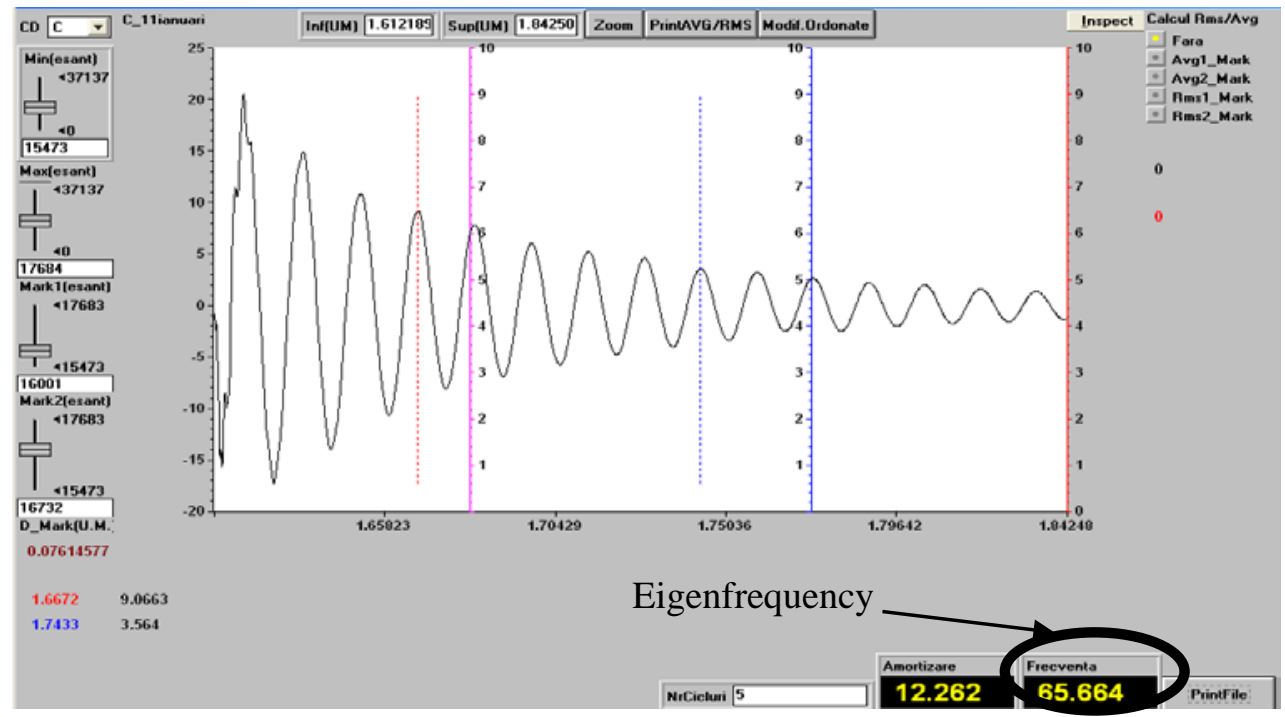


Figure 3: Eigenfrequency determination (sample 1, free length $29 \mathrm{~cm}$ )

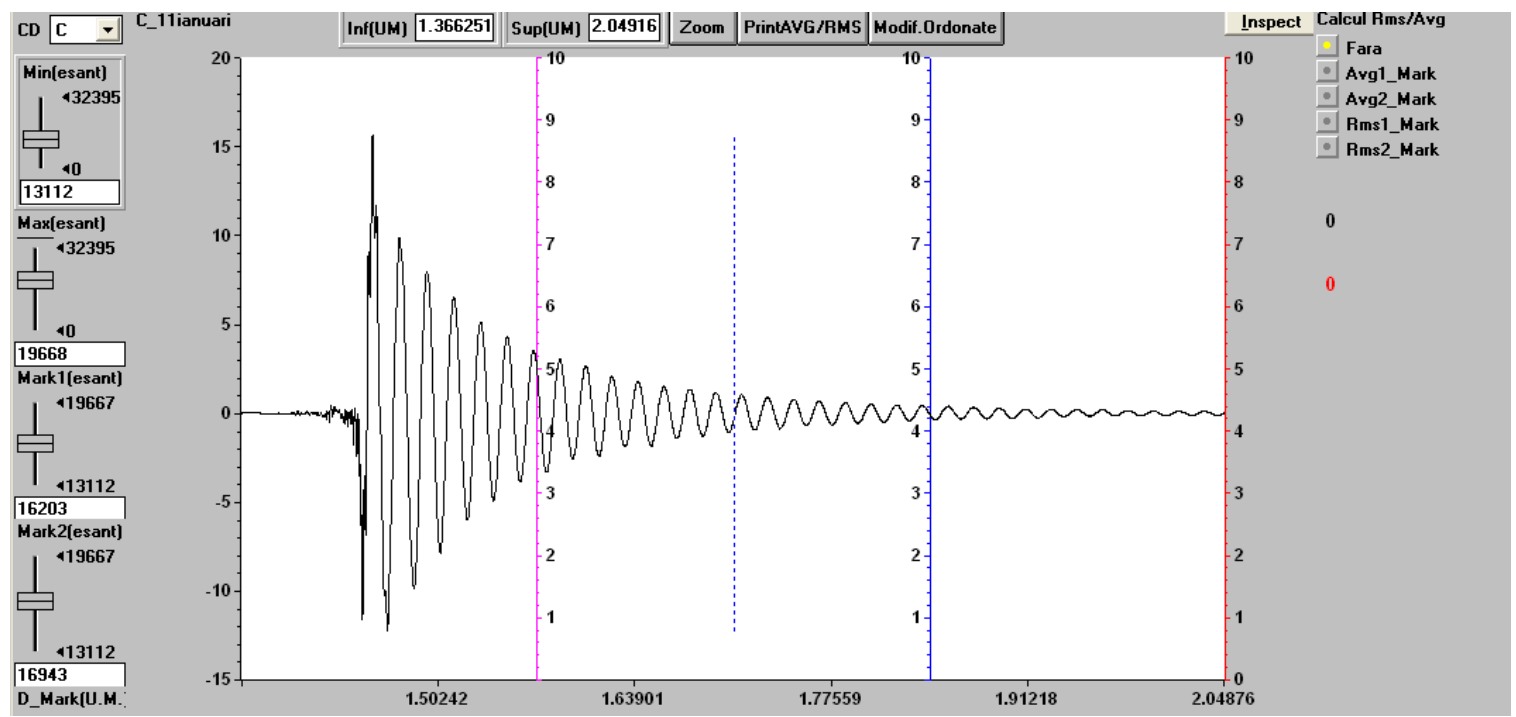

Figure 4: Experimental recordings (sample 1, free length $32 \mathrm{~cm}$ )

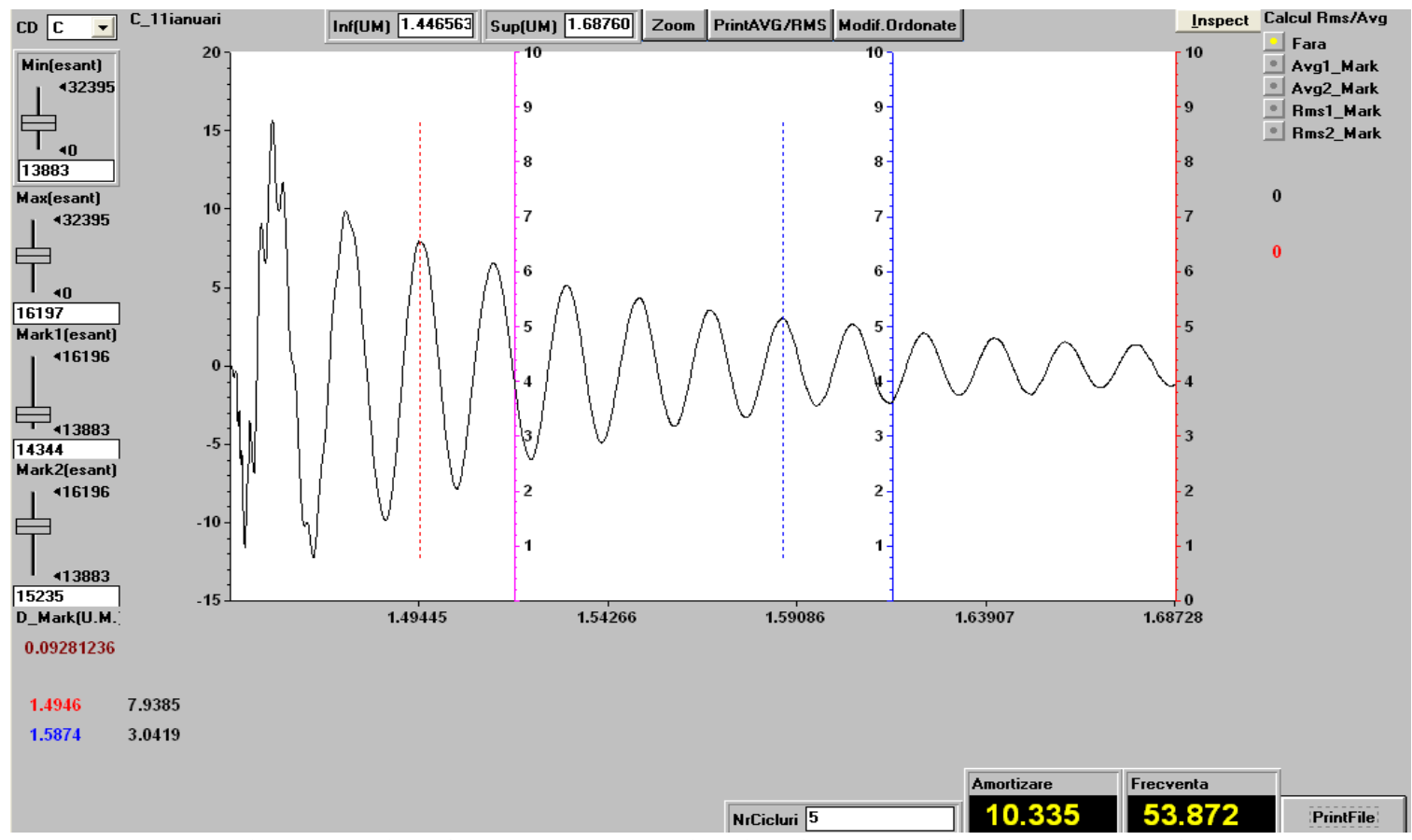

Figure 5: Eigenfrequency determination (sample 1, free length $32 \mathrm{~cm}$ ) 


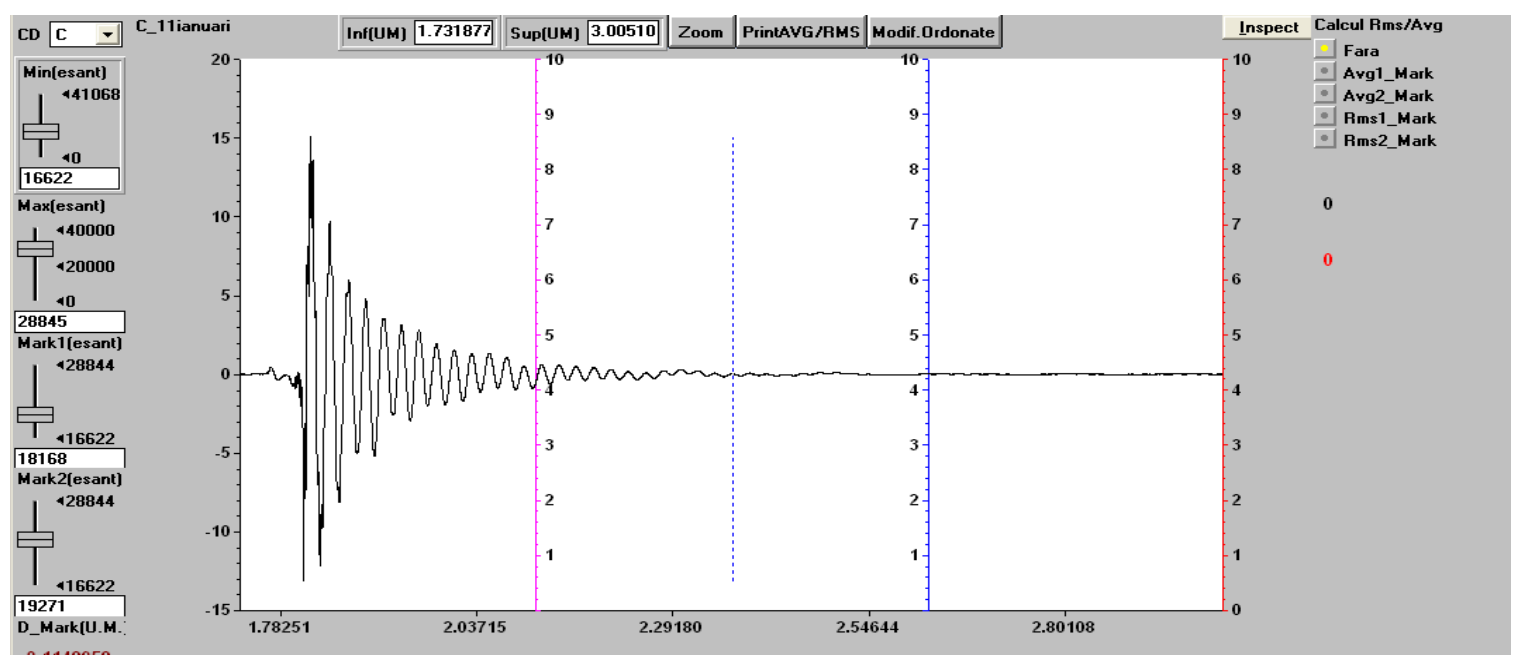

Figure 6: Experimental recordings (sample 1, free length $32 \mathrm{~cm}$ )

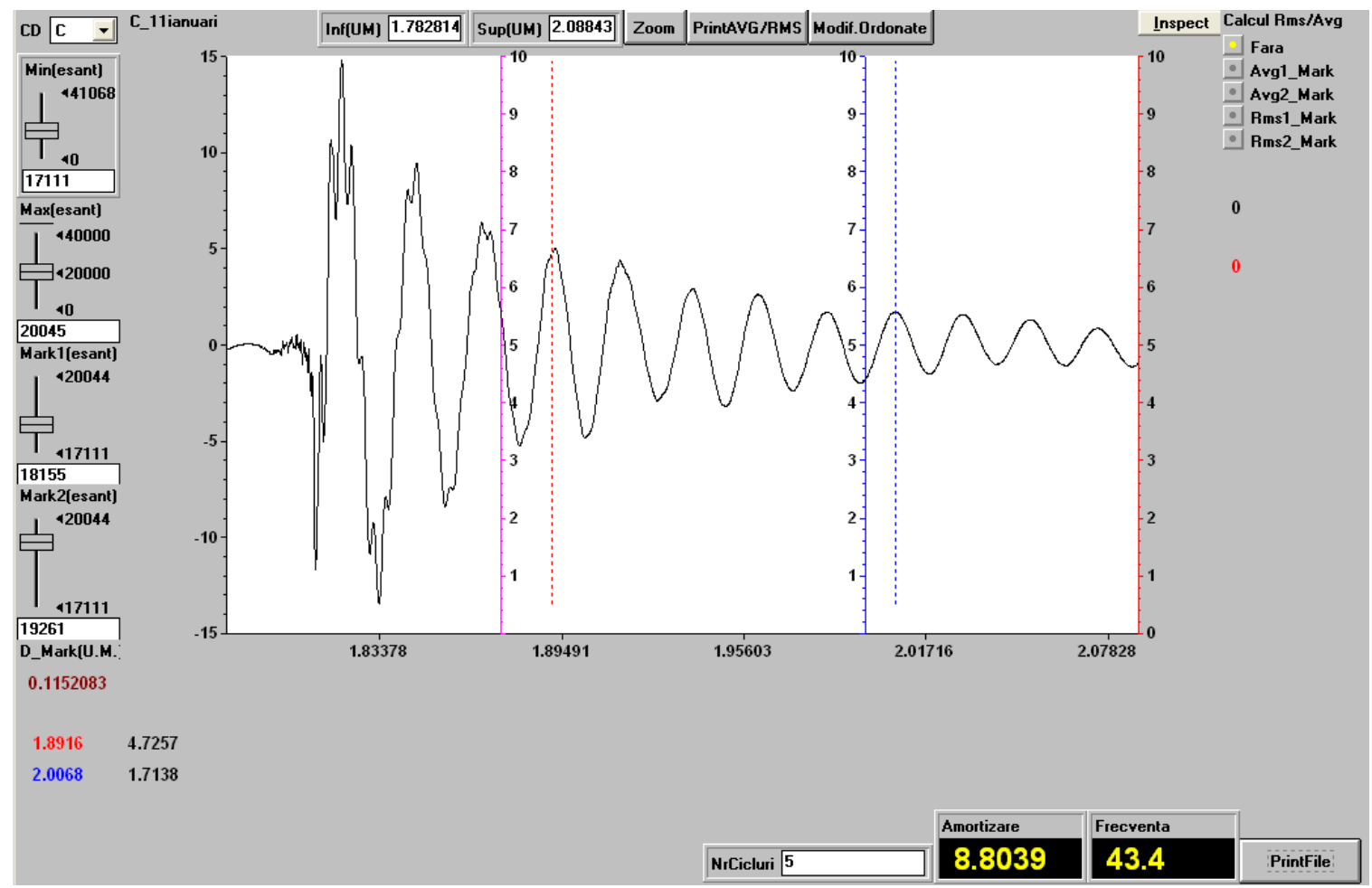

Figure 7: Eigenfrequency determination (sample 1, free length $35 \mathrm{~cm}$ )

The geometrical characteristics, mechanical properties and the experimental obtained data for all the samples are written in table 1.

Table 1: Samples 1, 2 and 3 characteristics and experimental eigenfrequency

\begin{tabular}{|c|c|c|c|c|}
\hline $\begin{array}{c}\text { Width } \\
{[\mathbf{c m}]}\end{array}$ & $\begin{array}{c}\text { Thickness } \\
{[\mathbf{c m}]}\end{array}$ & Free length $[\mathbf{c m}]$ & Frequency [1/s] & $\begin{array}{c}\text { Sample } \\
\text { number }\end{array}$ \\
\hline 6 & 1 & 29 & 65.664 & 1 \\
\hline 6 & 1 & 32 & 53.872 & 1 \\
\hline 6 & 1 & 35 & 43.4 & 1 \\
\hline 6 & 1.5 & 29 & 88.561 & 2 \\
\hline 6 & 1.5 & 32 & 73.949 & 2 \\
\hline 6 & 1.5 & 35 & 58.182 & 2 \\
\hline 6 & 2 & 29 & 110.85 & 3 \\
\hline 6 & 2 & 32 & 93.567 & 3 \\
\hline 6 & 2 & 35 & 73.62 & 3 \\
\hline
\end{tabular}




\begin{tabular}{|c|c|c|c|c|}
\hline $\begin{array}{c}\text { Density } \\
{\left[\mathbf{k g} / \mathbf{m}^{\mathbf{3}} \mathbf{]}\right.}\end{array}$ & Mass $\mathbf{[ g ]}$ & $\begin{array}{c}\text { Specific mass } \\
{[\mathbf{k g} / \mathbf{m}]}\end{array}$ & $\begin{array}{c}\text { Number of carbon } \\
\text { layers }\end{array}$ & Core \\
\hline 225 & 54 & 0.135 & 1 & Honeycomb \\
\hline 225 & 54 & 0.135 & 1 & Honeycomb \\
\hline 225 & 54 & 0.135 & 1 & Honeycomb \\
\hline 161.111 & 58 & 0.145 & 1 & Honeycomb \\
\hline 161.111 & 58 & 0.145 & 1 & Honeycomb \\
\hline 161.111 & 58 & 0.145 & 1 & Honeycomb \\
\hline 154.167 & 74 & 0.185 & 1 & Honeycomb \\
\hline 154.167 & 74 & 0.185 & 1 & Honeycomb \\
\hline 154.167 & 74 & 0.185 & 1 & Honeycomb \\
\hline
\end{tabular}

The eigenfrequency variation versus the samples free length is presented in fig. 8. According to [4], if the free vibrations are recorded and the eigenfrequency is determined from them, the formula (2) can be used for flexural rigidity calculus.

$E I=\psi \cdot 10^{-12} \cdot \rho \cdot A \cdot v^{2}$

In (2) I have marked with: $\rho$ the material density, $A$ the transversal area, $v$ the eigenfrequency and $\psi$ is a constant which depends of the bars free length in $\mathrm{mm}$, constant $\pi$ and the first root of the equation $(\operatorname{ch}(\zeta) \cos (\zeta)+1)^{2}=0$ obtained from the bars ends condition $\left(\psi \approx 2,259 \cdot 10^{10}\right.$ if the bars have $29 \mathrm{~cm}$ free length; $\psi=3,349 \cdot 10^{10}$ if the bars have $32 \mathrm{~cm}$ free length; $\psi=4,793 \cdot 10^{10}$ if the bars have $35 \mathrm{~cm}$ free length).

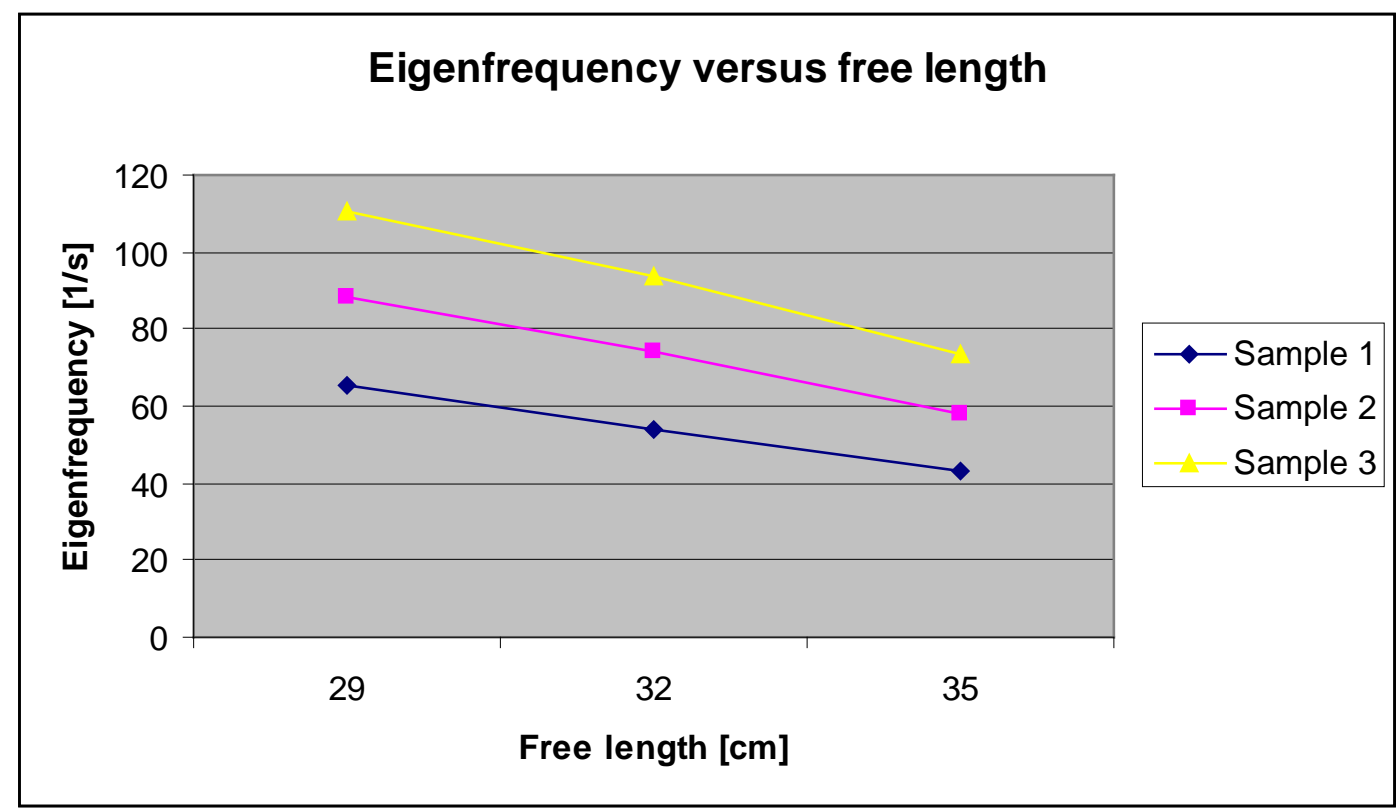

Figure 8: Eigenfrequency versus the samples free length

The obtained flexural rigidity for every free length is written in table 2 . In order to calculate the final flexural rigidity, the arithmetic mean was made between the three values which correspond to the samples free lengths (table 2).

Table 2: Samples 1, 2 and 3 flexural rigidity

\begin{tabular}{|c|c|c|}
\hline $\begin{array}{c}\text { Sample } \\
\text { number }\end{array}$ & $\begin{array}{c}\text { Flexural } \\
\text { rigidity } \\
{\left[\mathrm{Nm}^{2}\right]}\end{array}$ & $\begin{array}{c}\text { Flexural } \\
\text { rigidity } \\
\text { arithmetic } \\
\text { mean } \\
{\left[\mathrm{Nm}^{2}\right]}\end{array}$ \\
\hline 1 & 13.15 & \multirow{2}{*}{12.82} \\
\hline 1 & 13.122 & \\
\hline 1 & 12.188 & \\
\hline 2 & 25.692 & \multirow{2}{*}{25.25867} \\
\hline
\end{tabular}




\begin{tabular}{|l|l|l|}
\hline 2 & 23.527 & \\
\hline 3 & 51.356 & \multirow{3}{*}{51.221} \\
\hline 3 & 54.246 & \\
\hline 3 & 48.061 & \\
\hline
\end{tabular}

\section{Conclusions}

In this paper, starting from the free vibrations, I have established a procedure to determine the flexural rigidity for composite sandwich bars with polypropylene honeycomb core. I consider that, the added value of this paper is:

- building some new composite materials, from classical ones (polypropylene honeycomb core, carbon fiber and epoxy resin) combined in an original way;

- the obtained values for the eigenfrequency of the first eigenmode;

- the obtained values for the flexural rigidity;

- the experimental montage (the bar clamped at one end and free at the other).

The studied materials can be used in: machine building technology (for building the frames for machines like the turning, milling, boring machines and so on), vehicles and transports (for building the planes floor, parts of cars, bus, trucks bodies and so on) or civil constructions (for walls in order to absorb the vibration, for lightweight structures and so on).

\section{Acknowledgement}

This work was supported by the strategic grant POSDRU/159/1.5/S/133255, Project ID 133255 (2014), co-financed by the European Social Fund within the Sectorial Operational Program Human Resourced Development 2007-2013.

\section{References}

1. Oya, A., Kasahara, N., Horigome, R., Structure of porous carbon-fiber from phenolic polymer containing polystyrene microbeads, Journal of Materials Science Letters, Vol. 20, pp. 409-411, (2001).

2. Lukyanov, A., A., Effect of fiber orientation on the structure of shock waves in carbon fiber-epoxy composites, Mechanics of Composite Materials, Vol. 47, No. 6, pp. 617-626, (2012).

3. Stănescu, N., M., Bolcu, D., Pastramă, S., D., Ciucă, I., Manea, I., Baciu, F., Determination of damping factor, to vibrations of composite bars, reinforced with carbon and kevlar texture, Materiale Plastice, Vol. 47, No. 4, pp. 492-496, (2010).

4. Burada, C., O., Miriţoiu, C., M., Bolcu, D., Stănescu, M., M., Experimental determinations of the damping factor and stiffness for new sandwich platbands with different reinforcement and core, Revista Română de Materiale/Romanian Journal of Materials, Vol. 44, No. 4, pp. 405-413, (2014).

5. Voicu, R., Structural characterization and mechanical behaviour of carbon fiber/epoxy composites for aeronautical field, Materiale Plastice, Vol. 49, No. 1, pp. 34-40, (2012).

6. Burada, C., Determinări practice în laboratoarele de analiză şi încercări pentru construcţii, Universitaria, Craiova, (2010).

7. Burada, C., Încercări de laborator pentru materiale de construcţii, Universitaria, Craiova, (2011).

8. Kamae, T., Drzal, L., T., Carbon fiber/epoxy composite property enhacement through incorporation of carbon nanotubes at the fiber-matrix interphase- Part I: The development of carbon nanotube coated carbon fibers and the evaluation of their adhesion, Composites Part A: Applied Science and Manufacturing, Vol. 43, No. 9, pp. 1569-1577, (2012).

9. Kumar, B., G., Singh, R., P., Nakamura, T., Degradation of carbon fiber-reinforced epoxy composites by ultraviolet radiation and condensation, Journal of Composite Materials, Vol. 36, No. 24, pp. 2713-2721, (2002).

10. Baurova, N., I., Surface structure of fractured carbon-fiber composites before and after climatic aging, Fiber chemistry, Vol. 46, No. 4, pp. 241-244, (2014). 